\title{
MIGUEL MOYA Y LA REVISTA LA AMÉRICA (1879-1882)
}

\author{
José Miguel GonZÁLEZ SORIANO \\ jmgonzalezsoriano@gmail.com \\ Universidad Complutense de Madrid
}

\section{Resumen}

En 1879, un año clave dentro de su trayectoria profesional, el periodista, político y empresario Miguel Moya comenzó a escribir en la revista quincenal La América, cabecera doctrinal de las más importantes, longevas y difundidas de todo el siglo XIX español. En ella se ocuparía, durante algo más de dos años, hasta marzo de 1882, de efectuar la crónica de política interior y de actualidad cultural, al mismo tiempo que su maestro y amigo Emilio Castelar llevaba a cabo el comentario de la política exterior. Su lectura resulta hoy de gran interés y amenidad para seguir de cerca la vida pública de nuestro país durante el intervalo que duró su colaboración, y proporcionó a su autor un decisivo espaldarazo intelectual, además de servirle de plataforma de difusión para sus múltiples actividades político-sociales.

Palabras clave: Miguel Moya, La América, crónica general, política, cultura, sociedad, siglo XIX, republicanismo, librecambio, Sociedad Abolicionista.

\begin{abstract}
In 1879 , a key year for his career path, the journalist, politician, and entrepreneur Miguel Moya began his contribution at the fortnightly magazine La América, one of the most important, long-lasting, and widely spread publications throughout the entire $19^{\text {th }}$ century. For over two years, until March 1882, he wrote on domestic policy and the contemporary culture scene, while his master and friend Emilio Castelar analyzed foreign policy issues. His interesting articles offer a close follow-up of Spain's public life during the period of his contribution as a journalist. They also helped to boost his intellectual prestige and became a useful way of promoting his various socio-political initiatives.
\end{abstract}

Keywords: Miguel Moya, La América, regular feature, policy, culture, society, $19^{\text {th }}$ century, republicanism, free trade, Abolitionist Society.

Anales, 26, 2014, pp. 213-237

DOI: 10.14198/ALEUA.2014.26.09 
En su ensayo histórico sobre El Ateneo de Madrid, Rafael María de Labra señalaba que, en el año 1879, «se inició en la vida general, política e intelectual de España un movimiento poco estudiado aún por los escasos aficionados de nuestro país a los estudios de historia contemporánea». Hacía referencia Labra al fin de la guerra separatista en Cuba, la entrada de diputados y senadores cubanos en las Cortes, la de parlamentarios republicanos con el carácter de tales... Y también, «declárase habilitado para ocupar el poder al Partido Liberal, que aceptando la Constitución del 76 pretende llevar a su desarrollo algunas de las inspiraciones de 1869» (Labra, 2010: 217). Igualmente, 1879 fue un año clave en la biografía del periodista, político y empresario Miguel Moya Ojanguren (1856-1920): ingresó en la redacción de La Democracia, firmando su manifiesto inaugural; publicó su primer libro, Conflictos entre los poderes del Estado, a raíz de una memoria que le valdría ser condecorado por la Academia de Jurisprudencia; entró a formar parte, como secretario, de la Asociación para la Reforma de los Aranceles de Aduanas y la Sociedad Abolicionista Española, ambas entidades reinauguradas aquel año; y sobre todo, a partir del mes de junio pasaría a integrar la redacción de El Liberal, una cabecera trascendental en su trayectoria periodística, a la cual quedaría ligado durante el resto de su vida. Pero además, desde el mes de diciembre empezaría a colaborar igualmente en la revista quincenal La América, cabecera doctrinal de las más importantes, longevas y difundidas de todo el siglo XIX español.

Nacido en la madrileña calle del Salitre, el contacto con el mundo de los periódicos y de la política no le llegó a Miguel Moya por vía directa familiar y fue, paradójicamente, el empeño de su padre, comerciante de telas, en que estudiase la licenciatura en Derecho lo que le condujo al mundo del periodismo. En 1874, con tan solo dieciocho años de edad, Moya obtenía su titulación en Leyes, pero al ser necesario por legislación, en aquella época, haber cumplido los veintiuno para poder colegiarse, hubo de optar, en un primer momento, por su otra vocación: la de periodista y escritor. Su primera salida laboral la iba a encontrar ante la mesa de redacción de un diario, La Iberia, órgano de Sagasta, en donde lograba sentar plaza como meritorio casi al mismo tiempo que otro joven amigo suyo y compañero de estudios universitarios, José Ortega Munilla; ambos, con el paso del tiempo, dos de las figuras más célebres e influyentes de la prensa en España. Juntos fundarían a continuación una original revista taurina, El Chiclanero, que redactaban y vendían a los aficionados, cada vez que se celebraba una corrida en la plaza de toros de Madrid, apenas dos horas después de finalizada la misma. Posteriormente, la siguiente parada periodística de Miguel Moya, ya sin la compañía de Ortega Munilla, tendría lugar en el diario constitucionalista La Mañana; y mientras iba en aumento su 
consideración como ingenioso y competente autor de -sobre todo- artículos festivos y de costumbres, su carrera iba a dar un nuevo y más decisivo paso al ser nombrado, con apenas veintiún años, director del semanario El Comercio Español, portavoz del Círculo de la Unión Mercantil de Madrid, puesto en el que permanecería diez años, hasta 1887. A pesar de su juventud, Moya conocía desde dentro el comercio madrileño, desde la familiaridad con la tienda de tejidos propiedad de sus padres; y además de las relaciones sociales que podía proporcionarle su presencia en instituciones como el Círculo Mercantil o la Academia de Jurisprudencia, tras su paso por La Iberia y La Mañana formaba parte ya, enteramente, de los ambientes liberales y progresistas de la capital.

En las nuevas coordenadas sociopolíticas consolidadas a partir de la época isabelina, «la poesía, el cuadro de costumbres, el periódico llegarán a formar un continuo con la política, los partidos y el Gobierno». Si los clubes y ateneos eran el lugar de encuentro «... de la clase media como literata, las redacciones de los periódicos lo serán de esa misma clase media como política [...] pues se trata de una clase media que al no encontrar en Madrid grandes empresas industriales ni más carreras profesionales que las de abogado o médico, se dedicará, tras el necesario paso por la literatura y el periódico, que le abre las puertas de la sociedad, a la política, vía privilegiada de movilidad social». Moya, joven perteneciente a la clase media, licenciado en Derecho y con un futuro prometedor como escritor, tras su ascenso a la dirección de El Comercio Español y la fundación, a continuación, del semanario La Linterna en el seno del Ateneo, se hallaba inmerso, plenamente, en esa carrera de quien alcanzaba a ser «poeta, periodista y político sin contradicción interior alguna» (Juliá, Ringrose \& Segura, 2000: 335).

Poco tiempo después, en efecto, Moya ponía en marcha dentro de la «docta casa», en 1878, con su incipiente capacidad organizativa, una publicación titulada La Linterna, una pulcra revista literaria aunque ardorosa de juicio y de tintes irreverentes hacia buen número de autores ya consagrados, entonces en boga -lo cual casaba bien con el habitual espíritu crítico del Ateneo, sobre todo entre la juventud-, donde publicaría unas semblanzas de oradores de aquel tiempo, muy celebradas por sus contemporáneos, a las cuales debería -según confesión propia- su ingreso en El Liberal ${ }^{1}$, al recabar con ellas la atención de uno de sus principales fundadores, «Fernanflor» (Isidoro

1. «Preguntaron quién era el autor de las semblanzas de hombres del Ateneo y de la Academia de Jurisprudencia, que publicaba La Linterna; Conrado Solsona dijo que el autor era yo; y a Castro y Blanc, tío de Solsona, le comisionó la redacción de El Liberal para hablar conmigo. Me vio D. Ángel y me ofreció en El Liberal el puesto que yo quisiese. Acepté con todo entusiasmo» (González Fiol, 1911: 46). 
Fernández Flórez), quien reparó que detrás de esas acertadas y punzantes semblanzas de los principales personajes políticos de la época había un futuro gran hombre de los periódicos. A El Liberal, diario surgido el 31 de mayo de 1879 tras una escisión producida en el seno de El Imparcial, consagraría, pues, Miguel Moya buena parte de sus mayores y mejores esfuerzos, inicialmente como un miembro más -aunque destacado- de su plantilla, después como redactor-jefe, más tarde a cargo de su dirección y finalmente, junto a Antonio Sacristán, como propietario tras la muerte de «Fernanflor» en 1902. En sus páginas desarrollaría toda la extensa gama de la profesión, desde el artículo de fondo y la información parlamentaria a la crítica literaria o la teatral. Según él mismo, uno de los cometidos que más orgullo le produjo fue el redactar, junto a José Fernández Bremón y Eusebio Blasco, el suplemento literario del periódico, titulado «Entre páginas»; pero junto a él -aseguraría- podía emparejarse en honor, dentro de toda su trayectoria profesional, el de escribir a partir de 1879 la crónica de política interior y actualidad cultural en la revista La América, al mismo tiempo que Emilio Castelar -por cuyas dotes como orador y hombre público sintió siempre una gran admiración- llevaba a cabo el comentario de la política exterior (Abeytúa, 1919).

«Crónica hispano-americana», según rezaba su subtítulo, había sido fundada La América el 8 de marzo de 1857 -el mismo año que El Museo Universal, matriz de la emblemática La Ilustración Española y Americana- por el conocido progresista Eduardo Asquerino, embajador en Chile durante el gobierno de Espartero. En sus páginas, tanto los intelectuales españoles -con el renombrado Castelar, autor de su artículo inaugural, a la cabeza- como los propios escritores hispanoamericanos desplegaron su visión del otro lado del Atlántico desde aspectos tales como las relaciones bilaterales, el papel de los Estados Unidos, la emigración, las comunicaciones marítimas y telegráficas, la nacionalidad de los hijos de los emigrantes, los proyectos de reuniones científicas y de exposiciones, etc. ${ }^{2}$ Sin embargo, pese a su declarado espíritu panamericanista -fruto del relanzamiento decimonónico de las relaciones culturales con el Nuevo Continente, si bien aún de forma más sentimental que intelectual, desde repetidas escenografías, plagadas de fáciles tópicos,

2. En su artículo «Nuestro pensamiento» publicado en su segundo número ( 24 de marzo de 1857), Eduardo Asquerino asignaba a la nueva publicación tres fines primordiales: contribuir «a que se mantengan a toda costa, como una parte muy considerable de la Madre Patria» el archipiélago filipino y las Antillas; fomentar y defender «los elementos morales y materiales de nuestra raza [...] estrechando los vínculos de fraternidad y los lazos de común interés» con las repúblicas de América; por último, «la unión de España y Portugal es la más lisonjera de nuestras esperanzas». 
sobre los lazos cordiales entre España y América- era evidente, asimismo, su proyección interior, dada la actividad política e ideológica de su fundador; y así, La América trataría igualmente "principios doctrinales generales que desembocarían en la Revolución de septiembre de 1868» (Gómez Aparicio, 1967: 482-484). Tras ser nombrado embajador en Bruselas, Asquerino entregaría su dirección, en 1870, al reputado escritor y político Víctor Balaguer: el mismo que, pocos años después, pasaría a dirigir La Iberia cuando Moya y Ortega Munilla velaban sus primeras armas periodísticas.

En su último número de 1871, de fecha 28 de diciembre, La América anunciaba nuevos cambios en los contenidos de la revista «que harán de esta publicación lo que fue años antes», además del regreso de Asquerino -el nombre de Balaguer como director había desaparecido ya de su cabecera desde el mes de octubre anterior, tras su nombramiento como ministro de Ultramar- quien, no obstante, un año después cedería nuevamente la dirección a su hermano Eusebio, también periodista y escritor. Ya en 1875, consumada la Restauración monárquica, Eduardo Asquerino volvía otra vez a dirigir La América para reafirmar en ella su condición de adalid del liberalismo «y del partido político en que vengo militando desde mis primeros años» («El director de La América a sus suscriptores», La América, 13 de enero de 1875), pero las restricciones impuestas en materia de prensa abocarían a su desaparición poco después. No sería hasta el mes de febrero de 1879 cuando reanudase su publicación, tras la parcial apertura periodística consignada previamente por el gobierno de Cánovas, con Eduardo Asquerino de nuevo al frente. Su ejemplar de retorno venía encabezado -al igual que en la anterior etapa- por un artículo de Emilio Castelar, a quien acompañarían, como entonces, otros grandes escritores españoles y americanos, de dispar ideología incluso como Echegaray, Campoamor, Pi i Margall, Alarcón, Manuel Becerra, Juan Valera, Rafael María de Labra, Gabriel Rodríguez...

La primera crónica firmada por Miguel Moya aparecería en el último número de 1879, de fecha 28 de diciembre, una vez cumplida por La América una sanción de dos meses, impuesta por un artículo «lesivo» contra la institución monárquica. En ella, Moya pasaba revista a los acontecimientos políticos más relevantes de un año que había sido testigo, en sus compases finales, del estallido de la llamada «Guerra Chiquita» en Cuba, así como de la crisis del gobierno presidido por el general Martínez Campos, a quien reemplazaría Cánovas al frente de un ministerio que debía afrontar con urgencia la abolición de la esclavitud en la isla cubana -prevista en el pacto del Zanjón-, cuyo proyecto de ley había dividido con fuerza a los conservadores. El prestigio de su trayectoria y la gran categoría de su colaboración hacían indudablemente 
atractivo para Miguel Moya el poder escribir en La América; su presencia en ella coadyuvaría decisivamente a proporcionarle un espaldarazo intelectual a su carrera. Unos meses antes, sin embargo, de pasar a integrar su nómina de colaboradores, la revista se había mostrado muy severa al enjuiciar su obra Conflictos entre los poderes del Estado, una memoria acerca de las -posiblesdisyuntivas constitucionales leída previamente por él en sesión pública, el 18 de febrero de 1879, en la Academia de Jurisprudencia, prestigiosa corporación donde, durante generaciones, dieron sus primeros pasos como oradores «la mayor parte de los hombres que honrando el foro con su talento y la tribuna con su elocuencia alcanzaron en nuestro país gloria y renombre» y que, desde sus modestos bancos, «un día vieron el porvenir como un dios inventado por el deseo», como posteriormente evocaría el propio Moya en La América («Revista general», 28 de noviembre de 1880). El firmante de aquella reseña, Manuel Prieto, lanzaba un reproche de índole más bien personal a quien, desde La Linterna y otras cabeceras, se había dedicado a escrutar sin piedad cualidades y defectos de los oradores de la tribuna pública: «Estas y otras muchas consideraciones nos ha sugerido la lectura del libro de nuestro buen amigo el Sr. Moya, a quien hoy escaseamos alabanzas, que de muy buena voluntad le concederemos si, persistiendo en su laboriosidad, no tan solo escribe, sino que habla [...] La modestia puede ser traducida por falta de valor, y no es solo en la Academia de Jurisprudencia donde debe alzar su voz el autor de Conflictos entre los poderes del Estado» (Prieto, 1879).

\section{La «Revista General»}

En conjunto, los artículos publicados por Miguel Moya en La América figuran entre lo más destacado de su producción. Debido a la periodicidad quincenal de la revista, sus crónicas, de considerable tamaño, habían de contener el repaso generalizado de los asuntos más destacados de la actualidad española cada dos semanas; y su lectura resulta hoy de gran interés y amenidad para seguir de cerca la vida política y cultural de nuestro país durante el intervalo -algo más de dos años, hasta marzo de 1882- en que se mantuvo su colaboración. El esquema que sigue Moya a la hora de organizar el contenido de cada crónica para La América resulta siempre muy similar: suele comenzar de un modo literario, alegórico, para hacer referencia al mes o época del año en que se encuentra, exhibiendo su habitual ingenio en la pintura de costumbres y caracteres, ya cultivada por él en anteriores ocasiones; sigue a continuación el comentario, en tono más grave, de las actividades parlamentarias -cuando las Cortes llevaban a cabo sus sesiones- o de cualquier otro suceso político de trascendencia; prosigue después Moya con la relación de los acontecimientos 
culturales más señalados -las sesiones del Ateneo, algún acto académico, novedades bibliográficas- y de los estrenos teatrales más relevantes de la cartelera madrileña; y cerraba sus artículos, por último, con alguna anécdota chistosa o comentario en clave de humor -de desigual fortuna cómica, dicho sea de paso, por lo trivial-, a los que nuestro autor era buen aficionado.

Al principio, los trabajos de Miguel Moya para La América solían incluirse en las páginas finales de cada número, pero apenas transcurrido un año, concretamente a partir del 28 de noviembre de 1880, pasaron a encabezar el sumario de la revista bajo el rótulo «Revista general» tras disminuir la colaboración de Emilio Castelar («Revista europea») en ella; lo que motivará, además, la incorporación de referencias a la política internacional -parcela habitual dentro de La América del insigne tribuno- en las ya de por sí extensas crónicas de Miguel Moya: de ese modo, acontecimientos exteriores como la agitación irlandesa en su inveterado conflicto por la emancipación del gobierno de Inglaterra, el ascenso del liberal Gladstone como primer ministro británico en lugar del conservador Disraeli, el asesinato del zar Alejandro II y del presidente norteamericano Garfield, el conflicto bélico greco-otomano o la anexión francesa de Túnez hallarán cabida y comentario dentro del mosaico de actualidad elaborado quincenalmente por Moya. En clave nacional, el suceso político más destacado habría de ser la formación, durante la primavera de 1880, del llamado Partido Fusionista en el que, bajo la jefatura de Sagasta, antiguos liberales y constitucionalistas se concertaron con los centralistas de Alonso Martínez, herederos en su mayoría de la antigua Unión Liberal, y con otros elementos más moderados (el marqués de la Vega de Armijo, el conde de Xiquena), además de la adhesión, como puntales, de los generales Concha, Pavía, Jovellar, Martínez Campos y el conde de Balmaseda. Sellada esta alianza, que abarcaba tan amplio espectro político y militar, el fusionismo se revelaba, ya de entrada, como una impetuosa alternativa de poder para el Partido Conservador; y desde La América, Miguel Moya dejará constancia tanto de las ansias de sus miembros por alcanzar el gobierno como de sus dificultades para mantenerse cohesionados, dadas las personalidades tan dispares que constituían la nueva organización:

De estos debates y de los del Congreso resultaban en el fusionismo cuatro opiniones que no eran un programa de Gobierno, pero que podían ser una prueba de disidencia.

El general Martínez Campos, en los momentos de peligro, estaba decidido a poner siempre su espada al servicio de la Monarquía.

El Sr. Alonso Martínez, en cuanto la trompeta apocalíptica sonase, se iría a su casa a llorar en el retiro las desventuras de la política canovista.

El Sr. Sagasta aseguró que en todo caería del lado de la libertad. 
Y el Sr. Balaguer, considerando la forma de Gobierno cuestión accidental, no se mordía la lengua para decir que quería la libertad ante todo y sobre todo. ¿No es cierto que entre ellos no hay armonía posible? Pues, no obstante, una esperanza las ha conciliado. El Partido Fusionista, convencido de que nada puede esperar del cuerpo electoral, que es prisionero de guerra del Gobierno, todo lo aguarda del libre ejercicio de la regia prerrogativa («Revista general», La América, 8 de febrero de 1881).

Su momento llegaría a finales de febrero de 1881 cuando, ante la presión ejercida por las minorías en el Congreso y las veladas amenazas de pronunciamiento de buena parte del Ejército, el gobierno de Cánovas dimitía en pleno y Sagasta juraba el primer gabinete liberal en la Restauración. «Hemos sido profetas», aseveraba Miguel Moya en La América donde, un día antes de plantearse la crisis, había señalado en su crónica, fechada el 26, el irreversible agotamiento de la situación conservadora y cómo su caída «sería un triunfo de la opinión pública enfrente de la arbitrariedad y del pandillaje. Se ha empeñado en que el Sr. Cánovas se hunda con todo su orgullo olímpico y todas sus mentidas grandezas, y lo va a conseguir».

Dentro del espacio dedicado a la actualidad cultural, en lo referente a la crítica literaria Moya comentaría para La América, entre otros señalados títulos, El niño de la bola, de Pedro Antonio de Alarcón; La visión de Fray Martín, de Gaspar Núñez de Arce; Solos de Clarín, del reputado novelista, y crítico inflexible, Leopoldo Alas... El 8 de abril de 1881 reseñaba El señorito Octavio, una de las primeras novelas de su buen camarada y compañero universitario Armando Palacio Valdés ${ }^{3}$, y con anterioridad, el 28 de abril de 1880, igualmente hacía mención de la obra de otro condiscípulo suyo y compañero de lides profesionales, José Ortega Munilla («Las imágenes brotan de la pluma de Ortega como las flores en el campo llegando mayo. Leed El tren directo, y pensaréis lo mismo que yo»). Mayor presencia que las novedades bibliográficas tendrían, sin embargo, en sus crónicas los estrenos teatrales, al ser el género dramático, en una época aún pre-cinematográfica, el más popular por su contacto directo con el público, ante la dificultad para acceder a los libros en un país en el que el analfabetismo seguía siendo muy elevado, más de la mitad de la población española a fines del XIX. Comediógrafos del momento como José Fernández Bremón o Ceferino Palencia, algún dramaturgo consagrado como

3. «Yo no podía decir nada de Armando Palacio Valdés, ni exponerme a que los demás me recusaran por amistad manifiesta. Ha sido para todos crítico antes que novelista, y para mí amigo cariñoso antes que crítico, y si yo hubiese dicho que era un escritor elegante e ingenioso, que tenía bellísimo estilo, que pintaba con rara maestría, tal vez se habría creído que exageraba. Hoy ha dicho más que esto todo el mundo, y al repetirlo no hago sino unir mi voz al coro general de la crítica». 
Antonio García Gutiérrez y grandes compositores de zarzuela como Ruperto Chapí o Emilio Arrieta -quien en 1881 estrenaba su célebre Marina- aparecerán reseñados por Miguel Moya junto al autor, desde luego, más demandado de entonces, José de Echegaray. En contra de la opinión generalizada entre sus contemporáneos, Moya no gustaba en exceso de su teatro y, al comentar sus estrenos, aun procurando asentir con los elogios más comunes no podía evitar dispensarle ciertas apostillas irónicas. Como ejemplo, con cada obra nueva nuestro autor solía comenzar repitiendo, casi como un estribillo, en alusión a la doble condición echegarayesca de ingeniero y dramaturgo:

El Sr. Echegaray ha saltado de las ecuaciones a las escenas, del cálculo infinitesimal a los enredos de bastidores, de la teoría de Malthus al cementerio donde entierra a sus personajes, y no es raro que con la violencia del salto haya perdido el recuerdo de la realidad de la vida. El defecto principal de Mar sin orillas es ese olvido («Crónica», La América, 28 de diciembre de 1879).

Un año después, al reseñar otro estreno, La muerte en los labios, Moya volvería a insistir: «Ni vamos a recordar que Echegaray ha saltado de las ecuaciones a las escenas, del cálculo infinitesimal a los enredos de bastidores...», etc. Sin embargo, al representarse en marzo de 1881 El gran galeoto, la obra más estimada de Echegaray, reconocería en ella «un drama notabilísimo, conmovedor, lleno de situaciones sorprendentes y de pensamientos magníficos, tal vez la mejor de las producciones con que ha honrado nuestro teatro y ha tejido para su frente la corona del genio» («Revista general», La América, 28 de marzo de 1881). No podía -quizá- manifestarse de otro modo, en este caso, cuando dentro de su propio diario El Liberal el gran «Fernanflor» había asegurado que «El gran galeoto marca en Echegaray un nuevo autor. Forma clásica; personalidad vigorosa; corazón abundante: esto es hacer dramas» (Fernández Flórez, 1881), y al día siguiente el periódico abría, en su primera plana, una suscripción pública para materializar un homenaje a quien «no es un hombre público; es un hombre nacional; ilustración de un siglo; orgullo de un país», en la que todos los miembros de la redacción de El Liberal -incluido Moyaparticipaban con una contribución de 60 reales cada uno ( Homenaje a Echegaray», El Liberal, 21 de marzo de 1881).

Pero el gran acontecimiento cultural de nuestra «piel de toro», en el periodo en que Miguel Moya colaboró en La América, lo constituyó la conmemoración, mes y medio después del referido estreno de El gran galeoto, del segundo centenario del célebre dramaturgo Pedro Calderón de la Barca, para el cual una comisión encabezada por la Sociedad de Escritores y Artistas organizó una serie de festejos en la capital, entre el 22 y el 29 de mayo de 1881, siguiendo el ejemplo de lo acontecido en Lisboa -donde estuvo presente Moya- un 
año antes para honrar al poeta Camöens. Decoración en las calles, una exposición retrospectiva, representaciones de sus obras, veladas literarias, procesiones históricas, misas solemnes, desfile de carrozas, sesiones públicas en las Academias... Todo un despliegue de programación en torno a la figura del insigne escritor, arriesgada en principio ante la incógnita de la posible respuesta popular, pues no existía un precedente equiparable a semejantes fiestas, y que sin embargo resultaron, en opinión de Moya, «brillantísimas. Había el temor de caer en el ridículo, y hemos subido a lo sublime. España estaba orgullosa de contar entre sus hijos ilustres a Calderón; hoy puede estarlo de haber sabido honrarle dignamente. Nuestras esperanzas eran pequeñas, como el Monte de Helicón del Prado, y la realidad ha sido grande, como el Capitolio romano» («Revista general», La América, 8 de junio de 1881). También la prensa, como no podía ser menos, se sumaría al evento dedicándole en su mayoría números especiales, como el semanario del Círculo de la Unión Mercantil, dirigido por Moya, El Comercio Español, cuyo último número de mayo iba dedicado íntegro a la figura y la obra calderoniana; y La América, que adelantaría tres días su aparición -del 28 como acostumbraba a salir cada segunda quincena de mes, al 25- para coincidir con la fecha de la muerte de Calderón.

\section{Los «banquetes democráticos»}

Encontrándose la ya muy relevante personalidad de Miguel Moya inmersa, además del trabajo diario en la redacción de El Liberal y la dirección de El Comercio Español, en la campaña política y de organización del movimiento democrático-progresista, a la vez de participar en las campañas desarrolladas por la Sociedad Abolicionista Española y por la principal organización librecambista, reinaugurada en 1879 tras una primera etapa anterior de existencia, la Asociación para la Reforma de los Aranceles de Aduanas (A.R.A.A.), entidades de las cuales formaba parte, la tribuna de La América constituía para él, sin lugar a dudas, una valiosa plataforma de difusión y propaganda para tales actividades. Al narrarlas, Moya suele adoptar una actitud de «cronista», sazonada con frecuentes juicios y observaciones personales, mostrando sus lugares habituales de reunión desde un costumbrismo tradicional: la Academia de Jurisprudencia, el Ateneo, el Círculo de la Unión Mercantil..., espacios urbanos que pueblan sus artículos, dejando en ellos amplios frescos de su mundo. Reproduzcamos aquí la descripción evocadora que efectuaba de aquel último:

En la calle de Carretas [...] hay una casa de amplia fachada y lujosa apariencia, que todas las noches se hace notar por la confusa muchedumbre que se agolpa en sus puertas [...] Presentaba aún no hace muchos años, a la luz del 
gas, la casa a que nos referimos, tres cuadros dignos de que un pintor hábil en el dibujo y en el colorido los trasladase al lienzo. Abajo el teatro de la Infantil, el cantonalismo de la escena; comedias al minuto como las tarjetas de defunción, actores improvisados, baile cancanesco, público que aplaude a gritos como en una plaza de toros. Arriba la Tertulia Progresista, recuerdos y esperanzas, las agitaciones de la política que iban allí a morir tranquilas o a romperse furiosas [...] En el centro, el Círculo de Unión Mercantil, al principio un término medio entre la fiebre abrasadora de la política y la delirante alegría del can-can; después, una sociedad que defiende los sagrados intereses del comercio; que pide reformas, que protesta contra los privilegios, que da forma a las quejas justísimas de la clase mercantil española, que se hace aplaudir por la opinión y escuchar por los gobiernos.

El Círculo de la Unión Mercantil ofreció después una tribuna a los oradores más notables de nuestro país, y estos a ella acudieron ganosos de propaganda para sus opiniones [...] Los oradores que explicaron las conferencias que ahora reunidas en un elegante tomo acaban de publicarse y forman un libro importantísimo (Miguel Moya, «Revista general», La América, 8 de abril de 1881).

Se refería Miguel Moya a la edición -llevada a cabo, no de forma casual, en la imprenta de El Liberal- de las Conferencias del curso de 1879 a 1880 del Círculo de la Unión Mercantil, y que encabezaba un prólogo a cargo del propio Moya, del cual forma parte el texto entresacado de La América.

Con la aspiración de aglutinar las fuerzas dispersas del republicanismo en aras de concertar una «acción común democrática», se fundaba el llamado Partido Democrático-progresista tras las elecciones generales de 1879, mediante el pacto de los radicales de Ruiz Zorrilla y Cristino Martos con los republicanos históricos de Nicolás Salmerón (Dardé Morales, 1974: 444). A dicho pacto de coalición se sumaría a título personal José de Carvajal, miembro destacado del Partido Posibilista, pero no su elocuente jefe de filas, Castelar, dada su falta de entendimiento con Salmerón y con Manuel Ruiz Zorrilla. Quedaron fuera también del acuerdo los federalistas, cuya máxima figura continuaba siendo Pi i Margall, y Segismundo Moret que fundaría su propia organización política. El nuevo Partido Democrático-progresista vería la luz formalmente mediante un manifiesto a la opinión pública el 1 de abril de 1880, redactado por Echegaray y suscrito por 275 ex diputados y ex senadores y 21 periódicos y sus representantes. Desde una de aquellas publicaciones firmantes del manifiesto, La América, Miguel Moya comentaba los contenidos, significación e importancia del mismo:

Venciendo los contratiempos y las dificultades que en nuestra patria se oponen desde antiguo a la realización y conclusión de toda empresa generosa, ha aparecido el Manifiesto democrático-progresista [...] Formado por los antiguos radicales que supieron un día enlazar la monarquía con la democracia, 
y por una parte del republicanismo histórico [...] tiene la manifestación del Partido Democrático-progresista grandísima importancia política.

Por lo de democrático, dice el Manifiesto que proclama el Código político de 1869 con leves modificaciones, requeridas por la amplitud de las instituciones modernas; que anhela el servicio militar y la instrucción primaria obligatoria y universales; y que procurará, en cuanto a sus fuerzas toque, levantar y agigantar la conciencia pública por el sufragio y el Jurado [...] Por lo de progresista, aún significa más el nuevo partido, porque pone a su frente, como ejemplo imborrable, la honradez sin tacha y la abnegación política de una generación que nos ha dado la libertad trabajando sobre los huesos de sus mártires el alcázar santo de nuestras perseguidas ideas [...]

Erraría quien pensara por estos juicios que vemos en el Manifiesto democrático-progresista una obra perfecta. Ni lo es ni sus autores han imaginado que lo fuese [...] Su publicación ha sido un acto político trascendental; su carácter el de ser un paso hacia adelante. («Crónica», La América, 8 de abril de 1880).

Bajo un ambiente generalizado de optimismo y confianza, a lo largo del verano de 1880 la nueva organización se ocuparía de configurar sus comités provinciales y de verificar sus primeros actos públicos. Así, el 20 de diciembre de 1880 se celebraba en el madrileño restaurante de Fornos el banquete denominado de la «juventud democrática», donde, además de ser uno de sus organizadores, Miguel Moya se destacaría como orador en los brindis y, junto a él, otros futuros protagonistas de la vida pública española -singularmente, Alberto Aguilera, José Canalejas y Francos Rodríguez- lo que daría al acto, con el transcurrir del tiempo, una trascendencia histórica mayor. Estaban convocados al mismo los jóvenes demócratas que no hubieran sido miembros de las Cámaras ni ejercido cargos «que pudieran imprimir un carácter determinado a la reunión», advirtiéndose en el dorso de las invitaciones que «los que concurren al banquete entienden que en él no deben invocarse sino ideas y principios, omitiendo alusiones a personas y partidos determinados». Según explicaría el propio Moya en La América, el banquete no pretendía ser

...una protesta contra los jefes históricos de la democracia, ni se estableció al organizarle exclusión alguna. Era una protesta; la protesta del sentimiento liberal del país contra la política presente. Se quería manifestar por medio de un acto de adhesión a las ideas y a las soluciones de la democracia, que [...] se ha venido formando en nuestro país una juventud inmensa y entusiasta, cuyo ideal está formado por los principios generales de la democracia europea, y que esta juventud está resuelta a propagarlos y a defenderlos y a procurar su triunfo («Revista general», La América, 28 de diciembre de 1880).

Sin embargo, no todas las opiniones fueron coincidentes en esta apreciación ni estaba aún la anhelada fraternidad cerca de ser un hecho, pues no dejó de advertirse la ausencia de republicanos históricos, federales o posibilistas. 
Sin entrar en polémicas estériles ni rivalidades partidistas, dentro del mismo artículo Moya prefería, de acuerdo con el espíritu de la reunión, pensar en el futuro de forma más constructiva: «Que el movimiento iniciado por los jóvenes demócratas de Madrid, tenga eco en las provincias, y jadelante! Todo nos permite esperar». El de Fornos sería, de hecho, el primero de una serie de «banquetes democráticos» celebrados en todo el país cuyo objetivo, entre discursos y champán, consistía en que los elementos defensores de la República se concertasen para una acción común; y en los cuales intervendría Miguel Moya, en más de una ocasión, como orador. La situación política, no obstante, variaría de modo sustancial a raíz de la llamada al poder del Partido Fusionista, lo que provocó el desconcierto en las filas demócratas respecto a la conducta a seguir a partir de entonces: la actitud inicial de Martos y su grupo parlamentario fue de «benevolencia» hacia el nuevo Gobierno -una postura celebrada calurosamente por Moya- ${ }^{4}$, pero desde el exilio Ruiz Zorrilla hacía continuas llamadas a la no colaboración, al confiar únicamente en un levantamiento militar para el logro de las aspiraciones republicanas. Reunidos ambos líderes en Biarritz en el mes de junio, durante el verano se mantendrían abiertas ambas líneas de actuación, la subversiva de Ruiz Zorrilla en París y la legalista de Martos en España; y con este último, los jóvenes demócratas protagonistas de los «banquetes», como exponía Miguel Moya en La América:

Los acuerdos de las conferencias de Biarritz son demasiado públicos para que nosotros los reproduzcamos textualmente [...] La Junta directiva del Partido Democrático-progresista los aprobó con satisfacción, por más que a este acuerdo no se llegase sin pasar por dolorosas disidencias [...] Aceptada la política de benevolencia, sin que esto signifique que se prescinde de los antecedentes históricos del partido, mientras el Gobierno, caminando hacia la libertad, no se olvide de los compromisos solemnemente contraídos ante la opinión pública; convencido de la necesidad de concluir con los tribunales de apelación inacabables [...]; firme en la idea de la unión democrática por todos los medios de propaganda, el Partido Democrático-progresista podrá

4. Así, escribía en La América el 26 de febrero de 1881: «La actitud de benevolencia que enfrente del nuevo Gobierno ha tomado la democracia, solo aplausos merece. Quien ha sufrido con resignación la tiranía de una política conservadora seis años, no sería digno de la libertad si al solo anuncio de ella se aprestase a correr aventuras indisculpables». Un mes más tarde, matizaba que «la democracia aceptó la política de benevolencia porque ha visto en el cambio de gobierno el primer paso en el camino de sus esperanzas, no porque creyera que había llegado al término de su viaje. Censurar por sistema hubiera sido insensato; no aplaudir las reformas hechas, injusto; creer que hemos llegado a la tierra de Promisión es tanto como cerrar los ojos a toda nueva luz y el espíritu a toda nueva esperanza» («Revista general», 8 de abril de 1881).

Anales, 26, 2014, pp. 213-237 
ganar fama de fuerte y prestigioso en las próximas elecciones ( «evista general», La América, 28 de junio de 1881).

Aquella reunión, sin embargo, no había hecho sino debilitar a la formación; y los discretos resultados obtenidos en las elecciones generales del mes de agosto -donde los demócratas mantendrían, con todo, su representación parlamentaria con respecto a 1879_5 acentuaron aún más la división en su seno. «Doloroso es vivir separados, pero más doloroso es vivir unidos en la discordia», sentenciaba Moya en La América («Revista general», 8 de noviembre de 1881). La separación sobrevino una vez reunido el Comité Central del partido a finales de octubre; y la campaña de los «banquetes democráticos», en aras de la confraternidad, quedaba atrás apenas transcurrido un año desde su comienzo. Del partido, «en que aún se mantenían, al lado de Ruiz Zorrilla, personas de tanto valer como Salmerón y sus amigos» (Francos Rodríguez, 1918: 39-40), se separaron Martos, Montero Ríos, Romero Girón y Canalejas; y también les seguiría Moya, al menos ideológicamente, manifestando su apoyo a la lucha legal y a las declaraciones programáticas efectuadas tras la escisión: república liberal como forma de gobierno, la Constitución de 1869 como Código fundamental, negación de todo grado o tendencia de federalismo, ley de afinidad o de aproximación como única posible en su alianza con los demás partidos... ${ }^{6}$ Tras haber contribuido, sin que llegase a figurar en su Junta directiva, a la constitución del Partido Democrático-progresista, Miguel Moya volcará ahora su activismo en el área de la prensa y participando en dos organizaciones de carácter específico donde la cohesión entre sus componentes -aquí sí- habría de ser más constante y duradera: la Sociedad Abolicionista Española y la llamada «Asociación para la Reforma de los Aranceles de Aduanas» (A.R.A.A.).

5. Poco antes de celebrarse los comicios, Moya advertía que «si el Partido Democráticoprogresista va a la lucha electoral, a pesar de los grandes obstáculos que se oponen, no es porque confía en el triunfo, sino porque importa mucho que en la tribuna se defienda la causa de la democracia [...] Para los partidos gobernantes el terreno electoral es campo de batalla; para el Partido Democrático-progresista, campo de maniobras; aquellos, pelean por la precaria dominación del presente; éste, por la conquista segura del porvenir» («Revista general», La América, 28 de julio de 1881).

6. «Creyendo que estas son interpretaciones fieles de los principios que profesamos y que ha profesado siempre nuestro partido, las consignamos, porque son las únicas a que prestamos acatamiento, porque arrancan de lo más profundo de nuestra conciencia, y nos son impuestas, no por pasiones, aunque nobles, transitorias, sino por juicios severos y definitivos de nuestra razón» («Revista general», La América, 28 de noviembre de 1881). 


\section{Los mítines librecambistas}

La doctrina individualista de la escuela economista, junto con el krausismo, fueron las dos fuentes ideológicas principales en las que bebería la generación protagonista de la Revolución de 1868. Moya, heredero de aquella generación, trazaría las líneas principales de su perfil político desde el liberalismo progresista -con muy marcado acento sobre el abolicionismo-, el autonomismo en el Caribe español, el librecambismo económico y el republicanismo posibilista democrático, directamente inspirado por Castelar y Cristino Martos. En la época en que quedaba encargado de la dirección de El Comercio Español, comenzaban a experimentar un retroceso general las tesis librecambistas al quedar suspendida, con el primer gabinete conservador de la Restauración, la rebaja progresiva del arancel establecida por el ministro del Gobierno revolucionario Laureano Figuerola, instaurándose así una política comercial proteccionista que se acentuaría durante los años siguientes (Serrano Sanz, 1987). Del mismo modo hubieron de sentirlo los más firmes partidarios de la libertad de comercio cuando -sobre todo, a partir de 1877se movilizaron para reclamar la aplicación de la rebaja del arancel y difundir el liberalismo económico. Junto al magisterio ejercido en la Universidad, la principal vía de difusión de las opiniones de la escuela economista habría de ser la propaganda pública, bien a través de revistas especializadas, de la tribuna del Ateneo madrileño o de organizaciones como la Asociación para la Reforma de los Aranceles de Aduanas (A.R.A.A.), reinaugurada en 1879 tras una etapa inicial cuyo origen se remontaba veinte años atrás, fundada en el local de la Bolsa madrileña con Luis María Pastor como primer presidente y Gabriel Rodríguez como secretario general ${ }^{7}$, y que finalizó en 1870 al considerarse logrado su fin una vez decretada la reducción arancelaria y elevados sus principales representantes (Figuerola, Echegaray, Ruiz Gómez...) a la gobernación del país. Tras su reconstitución en la sede del Círculo de la Unión Mercantil, el 16 de abril de 1879, Miguel Moya formará parte de su Junta directiva al ser elegido como secretario, cargo que irá renovando en años sucesivos.

La celebración de mítines en diferentes locales y teatros de la capital de España habría de ser la actividad fundamental del A.R.A.A. en esta su segunda etapa, cuya existencia se prolongaría hasta, aproximadamente, 1895. Su primera prédica tendría lugar en el mismo local de la Bolsa -situado entonces

7. Sus bases se publicaron en el folleto Asociación para la Reforma de los Aranceles de Aduanas. Noticia de su origen y planteamiento, acta de la sesión inaugural y juicio formado por la prensa, Madrid, Imprenta de «La España Mercantil», 1859. 
en la calle Barquillo- donde, en 1859, habían dado comienzo sus primeros trabajos; y fueron numerosos los actos públicos que llegaría a celebrar, algunos muy concurridos -sobre todo, al principio- y de gran resonancia de cara a la opinión. En su condición de secretario, Moya figurará dentro de la nómina habitual de asistentes, ocupando un puesto en la mesa presidencial. En general, se encargaría dentro de la Asociación de llevar a cabo los trabajos burocráticos y de organización, pues serían otros integrantes, más expertos en temas económicos y de mayor renombre, los encargados de llevar la palabra en los mítines (Moret, Pedregal, Joaquín Costa, Gabriel Rodríguez...). En calidad de periodista, sin embargo, tomaba nota de cada discurso y de los detalles inherentes a dichos actos para publicar, al día siguiente, su reseña en El Liberal y también algún comentario dentro de La América, durante el tiempo que permaneció en ella. Al coincidir, en abril de 1880, su actividad en el A.R.A.A. con la publicación del Manifiesto inaugural del Partido Democrático-progresista, Moya escribiría en dicha revista unas líneas reveladoras de su ideario doctrinal, sosteniendo la libertad mercantil como cuna de todas las libertades:

En todas las sociedades, a la libertad política ha precedido la libertad de comercio, y a todos los recuerdos de beneficios perdidos se ha anticipado el recuerdo de las ventajas que al consumo reporta siempre la facilidad en el cambio de producción. Si la sanción de los derechos individuales favorece el engrandecimiento de la vida pública, que es el engrandecimiento de las sociedades, las ventajas de la reforma arancelaria de 1869 se demuestran con la elocuencia incontrastable de los números [... ] Para defender esa reforma y recabar nuevas adquisiciones [...] renació la Asociación para la Reforma de los Aranceles. Su vida es corta, pero laboriosa. En los meetings [...] ha logrado grandes triunfos y no es extraño. Defiende la verdad, y tiene por fiel aliado a la elocuencia («Crónica», La América, 28 de abril de 1880).

Uno de los mítines de mayor repercusión fue el celebrado en el teatro Real el 14 de noviembre de ese mismo año de 1880, para tratar sobre la necesidad de establecer un tratado comercial con Inglaterra que beneficiase a la agricultura de exportación. En La América, Moya resumiría, entre los intervinientes, «la palabra castiza, sonora, acerada y fácil del Sr. Rodríguez; la notable manera de exponer del señor Alonso de Beraza; los arranques elocuentes del Sr. Ruiz de Castañeda; las comparaciones ingeniosísimas del Sr. Echegaray; la clara dialéctica del Sr. Bona; el inimitable gracejo del Sr. Albareda; el aticismo y la intención de Sanromá y los periodos amenos, elegantes, acabados, llenos de imágenes, de Moret» («Revista general», La América, 28 de noviembre de 1880). Sin lugar a dudas, uno de los más señalados logros de aquella campaña librecambista fue la aclimatación del meeting en España, práctica tan 
importante después para la actividad política del país. Moya destacaba esta circunstancia de su popularización en la reseña del celebrado por el A.R.A.A. el 26 de junio de 1881, al resaltar su éxito de asistencia:

El meeting con que la Asociación para la Reforma de los Aranceles de Aduanas ha terminado sus trabajos, fue brillantísimo. Cuando la nueva y valiosa campaña de la Sociedad librecambista dio comienzo, no era raro ver en sus reuniones públicas comerciantes ilustrados, oradores del Ateneo, escritores distinguidos, cuantos comulgan en la noble y redentora religión de la ciencia y el trabajo. Pero las señoras estaban entonces en lastimosa minoría. Pero ahora ya es distinto. La costumbre de los meetings se ha generalizado; la prensa concede con justicia a estas manifestaciones influencia extraordinaria en la opinión pública; además de la utilidad que revisten las grandes enseñanzas que allí se aprenden, el arte hermosísimo de la palabra recibe de continuo culto ferviente, y no es raro que las señoras se disputen asistir a los que bien pudiéramos llamar certámenes de la justicia y de la elocuencia. Los palcos y las butacas ofrecían anoche aspecto brillantísimo («Revista general», La América, 8 de julio de 1881).

Las aduanas conformaban una fuente de ingresos muy importante para la Hacienda, lo que provocaba miedo a la hora de reformarlas; la pugna entre librecambistas y proteccionistas llegó a alcanzar así una gran intensidad. Los proteccionistas se agrupaban en torno a las asociaciones representantes de la industria textil catalana, que constituían el grupo de presión más organizado y constante, al apelar a la defensa de una industria nacional que se destruiría si se la obligaba a competir con las extranjeras; mientras que en el plano social trataban de atraerse a los obreros citando la amenaza del paro si se rebajaban los aranceles (Tortella Casares, 1993: 151-152). Para Miguel Moya, sin embargo,

...la pretensión de los proteccionistas de que el mercado nacional debe ser para los españoles [...] ha perdido, por virtud de los hechos, toda su fuerza y con ella ya no se puede engañar a nadie. ¿Quién ignora que los mismos que declaman contra el producto extranjero lo buscan con afán para sus necesidades, con preferencia al español, cuando les parece mejor y más barato? ¿Quién ignora que los corifeos del proteccionismo, que esas pocas industrias fabriles que tanto invocan el patriotismo contra el librecambio, pagan derechos muy bajos por los muchos artículos que traen de fuera de España, en tanto que venden los artículos que producen a un precio mucho más alto que el de los similares extranjeros, enormemente gravados por el arancel? ( Revista general», La América, 8 de agosto de 1881).

Con la subida al poder de los liberales, en 1881, se moderó ligeramente la política comercial, restituyéndose la rebaja en el arancel, mas la vuelta al Gobierno de los conservadores tres años después dejaría a la Base Quinta arancelaria suprimida de forma definitiva. Pero el factor decisivo que produjo el 
giro definitivo contra el librecambio fue el motivado por la llamada «crisis agrícola» europea: la persistente caída en los precios de los alimentos ante la competencia, más barata, del cereal americano, lo que abrió un periodo de proteccionismo internacional debido, principalmente, al activismo de los agricultores a favor del bando proteccionista. En España, el 31 de diciembre de 1891, un nuevo gobierno de Cánovas aprobaba un arancel al alza calificado de «muralla china» (Tortella Casares, 1993: 154-155) y, pese a sus esfuerzos, los éxitos oratorios de los librecambistas no se verían acompañados de ninguna reducción en las tarifas. Miguel Moya ya no renovaría más su cargo de secretario de la Asociación; y la escuela economista se consumiría lentamente en España al ritmo -casi- que marcaba la desaparición biológica de sus grandes figuras. El país había entrado en una etapa intensamente proteccionista, que se ratificaría con la Ley de Bases Arancelarias de 1906, que apuntalaba a la industria catalana y que fue promulgada bajo el Gobierno de un antiguo apóstol librecambista, Segismundo Moret: «iSe acabó el librecambio! 'Es cursi hablar de librecambio!», exclamaría un año después el escritor y periodista Luis Bello, sobrino del que fuera uno de los más destacados miembros del A.R.A.A., Ildefonso Trompeta: «Todos los folletos de propaganda están arrinconados no sé dónde, en algún sótano, y yo, mientras el negocio se arruinaba paso a paso, he escrito muchos versos en un papel con membrete, que decía: "Asociación para la Reforma de los Aranceles de Aduanas"» (Bello, 1907).

\section{La Sociedad Abolicionista Española}

Un final, indudablemente, mucho más feliz habría de tener la otra entidad con la que Moya vino, durante varios años, a sostener sendas campañas propagandísticas: la Sociedad Abolicionista Española, en la que tanta parte tomaron igualmente los economistas; de hecho, su fundación siguió, con pocos años de distancia, a la de la asociación librecambista ${ }^{8}$. La sesión inaugural de dicha Sociedad tuvo lugar el 2 de abril de 1865, bajo un ambiente generalizado de malestar que vaticinaba, una semana después, los sucesos trágicos de la noche de San Daniel. Ajena, según sus estatutos, a «todo interés de partido, todo exclusivismo de escuela y toda intolerancia de Iglesia», nacía con la finalidad de crear un estado de opinión que obligase a los poderes públicos a resolver

8. «Junto a los grupos [...] que representan la proyección del liberalismo español en las esferas filosófica, económica y política, no podía faltar algún otro que encarnase una nota muy característica de tal movimiento: el sentido filantrópico y humanitario» (Cacho Viu, 2010: 111). 
el problema de la esclavitud en las últimas posesiones españolas en América. Con el regreso, en el verano de 1866, de Narváez al poder, no tardó mucho la Sociedad en ser disuelta; pero tras el triunfo de la Gloriosa en 1868, se reorganizaría bajo la presidencia del krausista Fernando de Castro, celebrando una gran manifestación pública el 10 de enero de 1873 que recorrió las calles de Madrid, así como un mitin en el teatro Real, dos semanas después, que contribuyeron en gran medida a que, bajo la presidencia de Gobierno de Figueras, las Cortes republicanas aprobaran una ley por la cual se libertaba a los esclavos portorriqueños y a los que no estuvieran registrados como tales en el censo de Cuba. La Restauración monárquica hizo, no obstante, que por segunda vez se disolviese la Sociedad Abolicionista, que contaba ya con organizaciones semejantes en las colonias antillanas.

Paralizada así su actividad propagandística, tras la subida al poder del general Martínez Campos, el «héroe del Zanjón», los antiguos miembros de la Sociedad Abolicionista acordarían por unanimidad reconstituir nuevamente la asociación, reuniéndose el 9 noviembre de 1879 dentro de la Academia de Jurisprudencia para nombrar a su nueva Junta directiva, con Joaquín María Sanromá de presidente y, entre sus secretarios, Miguel Moya, miembro asimismo del A.R.A.A. como muchos otros de los componentes de la recién elegida Junta ${ }^{9}$. Moya sería encargado de configurar una comisión de propaganda de cara a la prensa, con una labor fundamentalmente organizativa y de difusión. Y es que, como afirmaba su amigo, el escritor festivo José Fernández Bremón,

Miguel Moya, cuyo retrato ya conocen nuestros lectores, pertenece a la nueva generación de periodistas, y forma en la primera línea de esa juventud. Activo y útil, hombre de pluma y de palabra, los círculos políticos, literarios e industriales le nombran secretario y le abruman de trabajo, que ejecuta con tal facilidad y acierto, que anima a ocasionarle más molestias: su firma figura al mismo tiempo en varios periódicos importantes; asiste a los estrenos; hace críticas, libros científicos y humorísticos; y viéndosele en todas partes, aun a las altas horas de la noche, y después del esfuerzo físico que supone la frecuentación de tantos sitios diferentes, y tan diversos trabajos intelectuales, jamás se notan en él síntomas de fatiga.

[...] Una noche, soñando con él, preguntábamos a uno de esos cicerones que todo lo explican en los sueños:

$-¿$ Cómo escribe tanto y bien?

9. Vid. «Sociedad Abolicionista», El Liberal, 10 de noviembre de 1879. Ya en un banquete previo celebrado en Fornos, Gumersindo de Azcárate había hecho «discretas observaciones de semejanza y conformidad de fines entre las sociedades librecambista y abolicionista, notadas con gran sentido práctico» (La Correspondencia de España, 23 de marzo de 1879).

Anales, 26, 2014, pp. 213-237 
-Mire V. su pluma.

Y me enseñó una locomotora delgadita, que acaba en un punzón.

$-¿$ Cómo puede moverse tanto?

-Tiene un gabán con alas.

Alcé la mirada, y vi a Moya sobre la torre de San José echando requiebros a una golondrina (Fernández Bremón, 1880) ${ }^{10}$.

La primera tarea a realizar sería la preparación de un gran mitin que debía verificarse en el mes de diciembre, cuando se estaba discutiendo en las Cortes la ley de Abolición; pero la vuelta de Cánovas a la Presidencia obligó a la Sociedad a suspenderlo, al considerarse inconveniente por ejercer presión añadida sobre los legisladores. A cambio, la Junta elevaría una exposición al Congreso, redactada por Labra y firmada por todos sus miembros solicitando, con razones enérgicas, la abolición inmediata de la esclavitud en Cuba, expresamente señalada en el Pacto del Zanjón, que el Gobierno se dispuso a acometer coincidiendo con nuevas agitaciones en la isla cubana que habían dado lugar, en agosto de 1879, a la «Guerra Chiquita», con la rebelión en las provincias de Oriente de los cabecillas locales independentistas, espoleados por José Martí. La esclavitud estaba lastrando el progreso de la agricultura, que necesitaba la transformación y mecanización de los ingenios azucareros; pero los propietarios de las plantaciones se resistían a la abolición si no se les indemnizaba por el valor de los esclavos, y su coste económico era inasumible para la economía española. Acelerados los trámites parlamentarios, el 13 de febrero de 1880 se promulgaba un sistema de transición, el patronato, por el cual los esclavos serían declarados libres pero sometidos aún al poder de sus amos durante un plazo de hasta ocho años ${ }^{11}$. En La América, Moya calificaría a la aprobada ley de «máscara de la esclavitud», rechazándola así por insincera y contradictoria:

Lo que antes llamaba todo el mundo esclavitud, los conservadores llaman ahora patronato; las palabras son diferentes, pero el espíritu es el mismo; el nombre de esclavo no sonará más en nuestros oídos; la infamia queda, sin embargo; al lado del artículo primero de la ley que dice: «Cesa el estado

10. Meses más tarde, Moya reconocía en La América que «debo a Fernández Bremón una de las críticas más cariñosas que ha escrito, le debo una grande amistad, le debo admiración entusiasta por sus méritos como escritor y por lo extraordinario de su talento» («Revista general», 8 de noviembre de 1881).

11. Con arreglo a sus términos, la Ley de 13-2-1880 de Abolición de la Esclavitud e Instauración del Patronato retenía a los esclavos junto a sus amos durante cuatro años para, transcurrido ese periodo, manumitirlos definitivamente por sorteo en razón de la cuarta parte cada año, con lo que, en un plazo total de ocho, la esclavitud quedaría extinguida. Ya en 1886, se publicaba una Real Orden suprimiendo definitivamente el sistema de patronato y, con él, la esclavitud en todo el territorio español. 
de la esclavitud en la isla de Cuba», el artículo segundo declarando que «el patronato será transmisible por todos los medios conocidos en derecho», es sangriento sarcasmo. ¡Libre un hombre que puede venderse! Proclamar que el esclavo es hombre en el artículo primero de la ley de Abolición, para condenarle en el segundo a la eterna y triste realidad de mercancía, sería imperdonable impiedad, si no fuese absurdo que el egoísmo vende por verdad fielmente aquilatada («Crónica», La América, 28 de enero de 1880).

En su propósito de agitar a la opinión pública, para lograr del primer Gobierno liberal una ley de abolición definitiva, el 26 de marzo de 1881 la Sociedad convocaba un gran mitin en el teatro Alhambra de Madrid. Con Miguel Moya sentado en la mesa presidencial, intervinieron Labra, García Alonso, Laureano Calderón... A este mitin le sucedería otro más concurrido aún el 1 de junio en el teatro Real ( $C$ Cuando cantó la Patti no había más gente en el teatro», aseguraba Moya) con el que la Sociedad se sumó, además, a los recientes actos de conmemoración en honor de Calderón de la Barca. Hablaron en él Azcárate, Labra y Gabriel Rodríguez, «trinidad elocuentísima -en palabras de Moya- en la que se pueden estudiar modelos distintos de oratoria: desde la del polemista de lógica inflexible y argumentar acerado y valiente, hasta la del artista de la palabra que pinta en cada párrafo un cuadro distinto y arrebata por su inspiración y brillantez» («Revista general», La América, 8 de junio de 1881). Entre un acto y otro, la Sociedad había constituido, además, un cuerpo de letrados para dar, de forma gratuita, cobertura legal a todos aquellos patrocinados negros que la necesitasen, en el caso de tener que realizar alguna denuncia.

Poco a poco, el antiesclavismo seguiría ganando terreno: además de la constitución de comités abolicionistas en Cuba, con influencia creciente en la sociedad cubana, en 1882 se fundaban el Círculo de Cocheros y la Divina Caridad de La Habana, sociedades propagandistas y de gentes de raza negra; en 1883 se procedía mediante decreto a la expurgación de los censos de los esclavos en Cuba y a la supresión del cepo y el grillete como castigos... La Sociedad continuó denunciando el incumplimiento de las disposiciones que regulaban el patronazgo y, en 1885, sacó a la luz pública el caso de una joven negra, Águeda, muerta a base de azotes en el ingenio España, propiedad del ministro de Gobernación Romero Robledo -que sería destituido en una crisis parcial- («La negrita Águeda», El Liberal, 4 de mayo de 1886). Al fin, bajo un nuevo gobierno liberal y tras una decisiva intervención parlamentaria de Rafael María de Labra, el Congreso votaba, en la sesión del 27 de julio de 1886, la autorización para abolir el patronato cubano. Con su presencia en los mítines, su labor desde la prensa y su participación en las tareas administrativas como secretario, Moya había también, sin duda, contribuido al éxito de la 
Sociedad Abolicionista en su última etapa. «Quizá no haya habido en España asociación popular de mayor perseverancia y éxitos tan completos. Ninguna la ha superado en resonancia internacional», aseveraba tiempo después su presidente Labra (2010: 231), una vez disuelta -esta vez, definitivamente- en 1888 .

\section{Fin de La América. El periodista «por antonomasia»}

Dentro del vasto panorama de actualidad político-cultural -y de difusión de sus propias actividades, según hemos ido repasando- provisto quincenalmente por Miguel Moya a los lectores de La América, no podían faltar, por último, de un modo inevitable las notas necrológicas: así, Adelardo López de Ayala, el gran dramaturgo, presidente del Congreso en el momento de su fallecimiento ${ }^{12}$; Ángel Fernández de los Ríos, periodista, político e historiador, muerto en el exilio; Juan Eugenio Hartzenbusch, autor de Los amantes de Teruel; el poeta Ventura Ruiz Aguilera; o el presidente del Ateneo, José Moreno Nieto: « ¿Quién no sabrá escribir su semblanza? Imaginación ardientísima, torrente de palabras, erudición prodigiosa [...] Modestia que seduce, erudición que asombraba, voz de irresistible elocuencia, Jeremías en el Ateneo... Ese era Moreno Nieto» («Revista general», La América, 26 de febrero de 1882). Todos ellos, y algunos más, formarán parte de la lista necrológica del periodo reseñado por Moya, junto a los dos obituarios que, sin duda, más sentimiento habrían de causar dentro de la redacción de La América: el del poeta José Selgas Carrasco, colaborador asiduo en sus páginas y, sobre todo, Eduardo Asquerino, su director, fallecido el 30 de septiembre de 1880 y a cuya semblanza dedicaría íntegra Miguel Moya su crónica del 8 de octubre. Ante su desaparición, su hermano Eusebio se encargaría nuevamente de dirigir la revista que, sin embargo, comenzaría a partir de entonces a entrar en un periodo irreversible de decadencia. La colaboración de Moya cesaría en marzo de 1882, tras aceptar la corresponsalía en Madrid del diario coruñés La Voz de Galicia, fundado en enero de ese año -y cuya publicación alcanza nuestros días-; y ya en su última etapa, La América pasaría a estar dirigida, a partir del 13 de septiembre de 1885, por el escritor Antonio Guerra y

12. «La primera y única vez que hablamos con el Sr. Ayala fue hace poco tiempo. Estaba en el Congreso, en su despacho, fuera de aquel sillón presidencial desde donde, como Neptuno con su tridente la furia de las olas, calmaba con la campanilla muchas tempestades parlamentarias [...] Apenas sí desde aquel día hasta hoy ha pasado un mes, y Ayala ya no existe. Recordando uno de sus discursos pudiéramos decir del gran poeta, que ayer celebrábamos su talento y hoy lloramos su muerte» ("Crónica», La América, 8 de enero de 1880). 
Alarcón, para acabar extinguiéndose definitivamente diez meses después, el 28 de julio de 1886 .

Tras su nombramiento como director de El Liberal en 1890, entregado a esa tarea serían contadísimas las ocasiones en que, a partir de entonces, Moya firmase artículos en sus páginas o en otras publicaciones: el escritor iba ya, poco a poco, cediendo paso, periodísticamente, al empresario y organizador. Con una frase que hizo fortuna, y se ha repetido en innumerables ocasiones, el escritor Antonio Espina (1993: 194-195) definía a Miguel Moya como «el periodista por antonomasia», que no es ni pretende ser otra cosa. Si bien esto no es cierto, dadas sus actividades políticas paralelas -diputado a Cortes, por ejemplo, en buen número de legislaturas de la Restauración, además de las anteriormente descritas-, de hombre público, a las que prestó siempre gran atención -sin olvidar lo difusos que eran por entonces, como hemos dicho, los límites entre la política y el periodismo, cuando prensa y Parlamento actuaban como verdaderos vasos comunicantes-, y su condición de jurista y posteriormente de empresario que asume decididamente para la prensa su carácter de negocio mercantil, sí podemos afirmar que Moya fue, por encima de todo, un periodista clave en su época, no solo por su faceta escritora sino -más aún-por la organizativa e institucional, alzándose como uno de los grandes precursores del periodismo moderno en nuestro país, en unos años decisivos, además, en la transformación y crecimiento de la prensa en España, fruto de los cambios motivados por los avances tecnológicos y de la ley de 1883 que garantizaba, en la Restauración, la libertad de expresión de cualquier causa política.

Cofundador de la primera Asociación de la Prensa de nuestro país, la de Madrid, en 1895 -que presidiría ininterrumpidamente durante veinticinco años, hasta pocos meses antes de morir en 1920-, organizador de la cadena de filiales de provincias de El Liberal -en Barcelona, Bilbao, Sevilla y Murcia-, su faceta más sobresaliente, sin embargo, consistió en promover y presidir, desde 1906, la Sociedad Editorial de España (SEDE), conocida popularmente como «el Trust», grupo periodístico de concentración de medios pionero en español, visto con temor por muchos de sus contemporáneos y criticado a menudo como monopolio empresarial y poder de presión político y social; y que, malogrado al fin, no por ello menos audaz y estimable. Primer «magnate» -en cierto modo- de la prensa en nuestro país, aunque a lo largo de su vida Miguel Moya se mantendría fiel a un ideario democrático, de liberalización de la monarquía desde una posición filo-republicana, en su época de redactor en La América buscaba, como tantos otros jóvenes españoles, el mayor acomodo posible dentro de la sociedad de su época; y su carácter abierto y posibilista le 
llevaría a compaginar de modo coherente la defensa del republicanismo -en su dimensión cívica- y la sintonía con algunas de las corrientes intelectuales más avanzadas (krausismo, liberalismo económico...) con una acreditada independencia, unas aparentemente firmes convicciones religiosas y, en fin, un sentido práctico que le llevaría a establecer buenas relaciones con casi todos los segmentos políticos y económicos del país, y tener acceso a las más altas instituciones privadas por derecho propio. Personalidad de prestigio dentro del periodismo español y comprometido en política, en ella surgiría, en palabras de Indalecio Prieto (1967, I: 327), «como diputado republicano independiente, muy afecto a Castelar, y como republicano independiente murió, aureolado de impoluta honestidad».

\section{Bibliografía citada}

AbEYTUA, Isaac: «Figuras del cuarto poder. Miguel Moya», La Mañana, 5 de agosto de 1919.

BELLO, Luis: «Del problema catalán. Los sentimientos», El Mundo, 15 de diciembre de 1907.

CACHO VIU, Vicente: La Institución Libre de Enseñanza, Madrid, Fundación Albéniz/Sociedad Estatal de Conmemoraciones Culturales, 2010.

DARDÉ Morales, Carlos: «Los partidos republicanos en la primera etapa de la Restauración (1875-1890)», en José María Jover Zamora (ed.), El siglo XIX en España: doce estudios, Barcelona, Planeta, 1974, pp. 433-464.

FERNÁNDEZ BREMÓN, José: «Crónica general», La Ilustración Española y Americana, 30 de diciembre de 1880 .

FERNÁNDEZ FLÓREZ, Isidoro («Fernanflor»): «Entre páginas. El gran galeoto», El Liberal, 20 de marzo de 1881.

Francos Rodríguez, José: La vida de Canalejas, Madrid, Tipografía de la «Revista de Archivos, Bibliotecas y Museos», 1918.

Gómez Aparicio, Pedro (1967): Historia del periodismo español. Desde la Gaceta de Madrid hasta el destronamiento de Isabel II, Madrid, Editora Nacional.

GonZÁLEZ FIOL, Enrique («El Bachiller Corchuelo»): «Nuestros grandes prestigios. Miguel Moya (confesiones de su vida y de su obra)», Por esos mundos, 195 (abril de 1911), pp. 440-454.

Julié, Santos, David Ringrose \& Cristina Segura: Madrid, historia de una capital, Madrid, Alianza, 2000.

LABRA, Rafael María de: El Ateneo de Madrid 1835-1905: notas históricas, Madrid, Ateneo, 2010.

PRIETO Y PRIETO, Manuel: «Conflictos entre los poderes del Estado», La América, 7 de junio de 1879. 
Prieto Tuero, Indalecio: Convulsiones de España. Pequeños detalles de grandes sucesos, vol. I, México, Oasis, 1967.

SERRANO SANZ, José María: El viraje proteccionista en la Restauración. La política comercial española, 1875-1895, Madrid, Siglo XXI, 1987.

TORTElla CASARES, Gabriel: «La economía española, 1830-1900», en Manuel Tuñón de Lara (ed.), Historia de España. VIII. Revolución burguesa, oligarquía y constitucionalismo (1834-1923), Madrid, Labor, 1993.

Fecha de recepción: 06/04/2014

Fecha de aceptación: 20/09/2014 